\title{
The role of ethical values in an expanded psychological contract
}

\author{
Dr Wayne O'Donohue \\ School of Management \\ University of Tasmania \\ and \\ Dr Lindsay Nelson \\ Trafalgar Management Services \\ Tasmania
}

\author{
Address for correspondence: \\ Wayne O'Donohue \\ Department of Employment Relations and Human Resurces \\ Griffith University \\ Gold Coast Australia 4222 \\ Telephone: +61755527583 Fax: +61755529206 \\ Email: w.odonohue@griffith.edu.au
}

Please cite as follows: O'Donohue, W. \& Nelson, L. 2009 The role of ethical values in an expanded psychological contract, Journal of Business Ethics, 90 (2): 251 - 263. DOI 10.1007/s10551-009-0040-1. 


\begin{abstract}
Social values and beliefs systems are playing an increasingly influential role in shaping the attitudes and behaviour of individuals and organizations towards the employment relationship. Many individuals seek a broader meaning in their work that will let them feel that they are contributing to the broader community. For many organizations, a willingness to behave ethically, and assume responsibility for social and environmental consequences of their activities, has become essential to maintaining their 'licence to operate'. The appearance of these trends in individual and organizational behaviour towards outcomes that are more explicitly congruent with ethical and social values has significant implications for understanding the psychological contracts being created today. In this paper, we examine issues associated with the psychological contract and ethical standards of behaviour, focussing both at the individual and organizational levels.
\end{abstract}

Key words: ethical values, codes of ethics, ethical climate, psychological contract

\title{
The role of ethical values in an expanded psychological contract
}

\section{Changing employment context}

The dynamic nature of the social context in which organizations have to operate today has raised the possibility that social values and beliefs systems are playing a more influential role than previously in shaping the attitudes and behaviour of individuals and organizations towards the employment relationship (Ashmos \& Duchon, 2000; Burr \& Thomson, 2002). Concerned about the negative impacts of business and its activities on their communities, many people are seeking improved social, environmental and ethical outcomes from organizations. As a consequence, the notion of corporate social responsibility, that is to say a willingness to behave ethically and assume responsibility for the social and environmental consequences of their activities, has for many organizations become essential to maintaining viability and their 'licence to operate' (Collier \& Esteban, 2007). The creation of an 'ethical climate' (Victor \& Cullen, 1988; Martin \& Cullen, 2006) and the institutionalisation of organizational ethics (Sims, 1991), through culture, structure, and promulgation of explicit codes of ethics and conduct to govern decision-making processes, are examples of how organizations are endeavouring to operationalise their corporate social responsibilities, and demonstrate to employees and community alike that they are behaving ethically in their activities and decision-making processes. Two examples below provide support for this view:

"Ethics and compliance is a fundamental part of a performance culture in a successful company. Ethical leadership is about each individual's decisions and actions with others." (Hewlett-Packard, 2007)

"[I]ntegrity is not a novel concept at Ford. It does, however, require a personal commitment by each of us to act ethically in a rapidly changing business environment and conform our actions to the high standards that we set for ourselves." (Ford Motor Company, 2007)

The appearance of these trends in organizational behaviour towards outcomes that are more explicitly congruent with established ethical values, social values and personal belief systems, has significant implications for understanding the changed basis on which psychological 
contracts are being created today by many employees and their organizations. Without such an understanding, the likelihood of an organization establishing and sustaining ethical decision-making processes effectively over the long-term, thus underpinning its viability and 'licence to operate' into the future, becomes problematic.

In this paper, we examine issues associated with the psychological contract and ethical standards of behaviour, focussing both at the individual and organizational levels. Of particular interest are the sources of such ethical standards, and tensions associated with their operation in psychological contracts in organizational settings.

\title{
What is the psychological contract
}

Since the 1990s, the majority of research into operationalising the concept of the psychological contract has adopted a cognitive-perceptual definitional approach (Millward \& Brewerton, 2000), that defines the psychological contract as:

\begin{abstract}
"the individual's belief in mutual obligations between that person and another party such as an employer ... This belief is predicated on the perception that a promise has been made (e.g. of employment or career opportunities) and a consideration offered in exchange for it (e.g. accepting a position, foregoing other job offers), binding the parties to some set of reciprocal obligations." (Rousseau \& Tijoriwala 1998, p. 679)
\end{abstract}

A psychological contract forms when an individual perceives that his or her contributions obligate the organization to reciprocate (or vice versa), and it is the individual's unilateral belief in the obligation of reciprocity that constitutes the contract (Rousseau, 1989). The mutuality inherent in the psychological contract is 'potentially idiosyncratic and unique for each person that agrees with it' (Rousseau 1995, p. 10). Therefore, the emphasis on the individual's subjective (cognitive-perceptual) experience is logical and necessary.

The established approach to date for operationalising the psychological contract has been to use a bidimensional (transactional/relational) interpretive framework to differentiate contract types on the basis of a content-based assessment (Rousseau, 1995). The transactional type has a focus on self-interest and an emphasis on economic and material contract terms. The relational type focuses on mutual interest and an emphasis on socio-emotional and nonmaterial contract terms. There is a general consensus in the literature that, rather than representing the opposite ends of a continuum, the relational and transactional concepts are conceptually distinct dimensions (Taylor \& Tekleab, 2004). Thus an employee may be simultaneously high or low on both dimensions.

\section{Expanding the interpretive framework for the psychological contract}

The established bidimensional (transactional/relational) interpretive framework has its roots very much in the beliefs and values domain of the individual with regard to his or her relationship with the organization, and accordingly much research to date has focussed on the psychological contract as a single dyadic (employee-organization) relationship. However, some researchers (for example Marks, 2001; McLean Parks et al., 1998) have argued that such an approach ignores specific empirical evidence that suggests psychological contracts can often encompass multiple relationships which operate not only within but also outside the organization as well as imply an interdependency of exchange. In other words, the established interpretive framework does not properly recognise the growing significance of the interrelatedness of the psychological contract and the social context (Coyle Shapiro et al., 2004), 
and that many individuals may now aim to make psychological contracts that align the transactional ("what's in it for me"), and the relational ("what's in it for us"), with the transpersonal ("what fits with me, how do we work together in the organization, and where is the fit with me, us, and the rest of society" (Burr \& Thomson, 2002, p. 7).

Under the established interpretive framework, the nature of the contributions exchanged in a psychological contract are interpreted as either economic (transactional) or socio-emotional (relational) in nature. However, the possibility that an individual's contributions may take other non-material forms, such as ideological contributions arising from an individual's desire to further a highly valued cause or principle (beyond self-interest), is overlooked (Thompson \& Bunderson, 2003). This means ideology-related contributions (for example, derived from an employee's adherence to a professional code of ethics) are conflated with socio-emotional contributions, and are not able to be recognised or interpreted as a distinctive element in an employee's psychological contract. On this point, there is a growing amount of empirical research starting to appear in the literature that supports the idea of ideology-related contributions as a separate element within the psychological contracts of professional employees in particular (e.g. Bunderson, 2001; author reference; author reference; author reference).

Table 1 shows an expanded general interpretive framework for the psychological contract incorporating the transactional, the relational, and the ideology-infused perspectives. Comparison of the 'salient beneficiary' characteristics highlights an essential distinction between the three perspectives. In the case of a transactional perspective, the individual's approach is egoistic and instrumental focussing on benefits to him or her self. For a relational perspective, the individual approach is collectivistic focussing on benefits flowing to both the individual and the organization. In the case of an ideology-infused perspective, however, the focus is shifted beyond the individual and the organization to a third party beneficiary, defined in general terms as society, some segment thereof, or an intangible principle. Thus the ideology-infused psychological contract reflects a principled and externally oriented model of human nature, where the notion of benefit may transcend personal gain in the eyes of an employee (Burr \& Thomson, 2002; Thompson \& Bunderson, 2003). 
Table 1: Expanded interpretive framework for psychological contracts

\begin{tabular}{|l|l|l|l|}
\multicolumn{1}{l|}{} & Transactional & Relational & Ideology-infused \\
\cline { 2 - 4 } & Scope & $\begin{array}{l}\text { Pervasive and } \\
\text { comprehensive }\end{array}$ & $\begin{array}{l}\text { Boundary less; } \\
\text { 'All' encompassing }\end{array}$ \\
\hline Time Frame & $\begin{array}{l}\text { Close-ended } \\
\text { Specific duration }\end{array}$ & $\begin{array}{l}\text { Open-ended } \\
\text { Indefinite duration }\end{array}$ & $\begin{array}{l}\text { Open-ended } \\
\text { Variable duration }\end{array}$ \\
\hline $\begin{array}{l}\text { Primary } \\
\text { currency }\end{array}$ & Economic & Socio-emotional & Ideological \\
\hline $\begin{array}{l}\text { Organization's } \\
\text { obligations }\end{array}$ & $\begin{array}{l}\text { Provide continued } \\
\text { employment, safe working } \\
\text { environment, fair } \\
\text { compensation }\end{array}$ & $\begin{array}{l}\text { Provide training, career } \\
\text { development, promotion } \\
\text { opportunities, long-term job } \\
\text { security }\end{array}$ & $\begin{array}{l}\text { Demonstrate credible } \\
\text { commitment to a valued } \\
\text { social cause }\end{array}$ \\
\hline $\begin{array}{l}\text { Individual's } \\
\text { obligations }\end{array}$ & $\begin{array}{l}\text { Fulfil formally specified role } \\
\text { requirements }\end{array}$ & $\begin{array}{l}\text { Fulfil generalised role } \\
\text { obligations; organizational } \\
\text { commitment and } \\
\text { involvement; organizational } \\
\text { citizenship behaviour }\end{array}$ & $\begin{array}{l}\text { Participate in the } \\
\text { organization's } \\
\text { mission/cause; } \\
\text { organizational and societal } \\
\text { citizenship behaviour }\end{array}$ \\
\hline $\begin{array}{l}\text { Salient } \\
\text { beneficiary }\end{array}$ & Self ('Me') & $\begin{array}{l}\text { Self and organizational } \\
\text { community ('We') }\end{array}$ & $\begin{array}{l}\text { Society, some segment } \\
\text { thereof, or an intangible } \\
\text { principle ('All') }\end{array}$ \\
\hline
\end{tabular}

Source: Adapted from Burr \& Thomson (2002) and Thompson \& Bunderson (2003)

Incorporating the concept of an ideology-infused psychological contract into the interpretive framework opens up new possibilities. Firstly, it broadens our understanding of what contributions might be exchanged under the psychological contract between an employee and the organization. Secondly, and perhaps more importantly, by broadening the notion of the salient beneficiary to include third parties, it also offers the prospect of a better understanding of how perceptions of breach and violation of a psychological contract might develop.

\section{Breach of the psychological contract}

Psychological contracts operate according to a number of general principles, one of the most fundamental being that the purpose of a contract is the production of mutual benefits. In today's dynamic organizational operating conditions, however, where the employment relationship has been destabilised, the possibility of mutual benefits as an ongoing outcome of the exchange of contributions under the psychological contract has been weakened. Indeed, research suggests that a majority of employees are likely to experience instances of nondelivery of contributions by the organization (Robinson \& Rousseau, 1994; Rousseau, 1995).

Individuals routinely assess the organization's actions in terms of what contributions they believe the organization has 'contracted' to deliver. When no discrepancy is perceived (with some variation tolerated within limits determined by the individual), the psychological contract remains in a steady state. However, if a discrepancy is observed, the individual will go through a cognitive process to determine whether the discrepancy has a negative or positive impact. If the latter is the case, the psychological contract is 'fine-tuned' and 'business as usual' recommences. On the other hand if a negative impact falling outside the limits of acceptable change is perceived, then the discrepancy is considered a 'breach' (Turnley \& Feldman, 1999). The level of emotional response will determine if the breach becomes a 'violation', that is the individual will experience an affective response which arises from an interpretation process that is cognitive, imperfect and not necessarily conscious in nature. A variety of factors, such as the scale of loss as well as the history and current health of the employment relationship, influence the level of affective response meaning that not all 
discrepancies become breaches, and not all breaches are elevated in significance to contract violations (Anderson \& Schalk, 1998; Morrison \& Robinson, 1997; Turnley \& Feldman, 1999).

Most research to date using the established bidimensional interpretive framework, has considered the consequences of non-delivery by one party, usually the organization, only in terms of its impact upon the self-interest of the other party, usually the employee, or on the collective interest of both parties. However, the expanded interpretive framework allows for the perception by an employee of a failure by the organization to deliver on contributions involving a third party beneficiary to be understood as a breach of the psychological contract, even though there has been no direct personal or material impact on the employee (Thompson $\&$ Bunderson, 2003). So, in addition to factors such as the scale of loss as well as the history and current health of the employment relationship, the extent to which non-delivery by the organization impacts upon the interest of a third party salient beneficiary, may well influence the employee's perception of a breach of the psychological contract.

In summary then, expansion of the interpretive framework for the psychological contract enables us to go beyond the confines of the transactional and relational parameters that have operated in much of the psychological contract research to date. It allows us to recognise that the boundaries of the individual-organization relationship are subjective and not immune to influences operating beyond those boundaries. Incorporation of the ideology into the interpretive framework for the psychological contract thus makes it possible to consider more effectively the role and influence of values and belief systems in today's changing employment context, with particular reference in this case to ethical standards of behaviour in the workplace.

\section{Ethical frameworks}

It is well established that individuals use mental models or schemas both cognitively and intuitively to make meaningful interpretations of the intent of others, events, and actions commonly encountered within the organization (Rousseau, 2001). Schema content springs from two general sources. Firstly, there is private internalised knowledge, such as the individual's personal values and beliefs, previous and current employment experiences, and an understanding of the values, beliefs and likely behaviours of others in the workplace. The personal moral values and beliefs that underpin an individual's ethical reasoning are an example of this form of private internalised knowledge. Secondly, there is collectively shared knowledge, such as knowledge and understandings of the values beliefs and behaviour of others validated as 'correct' by peers and colleagues, which operate in a normative fashion (Bloor \& Dawson, 1994; Rousseau, 1995). The perceptions individuals share regarding professional codes of ethics, and the 'ethical climate' (Victor \& Cullen, 1988) within their organizations, are two examples of this collective knowledge.

\section{Personal ethical values and beliefs}

Although ethics has been said to be the pursuit of the 'good life' (Takala, 2006), more precisely it concerns a standard of conduct, or a set of principles by which we as individuals live, and has to do with answering the question 'what ought I do?' rather than 'what shall I do?' (Weinberg \& Yandell, 1971). For the individual assessing and interpreting the organization's contributions and intentions with regard to the psychological contract, personal ethical values and beliefs about what constitutes right behaviour will form an important schematic element, the sophistication of which will reflect the level of the individual's cognitive moral development. Kohlberg (1984) and other researchers that followed him have 
identified three broad levels of individual moral development: the 'pre-conventional' level, which is the lowest level of development; the 'conventional' middle level; and the 'postconventional' level, which is the highest level of individual moral development. Individuals develop at different rates and do not always complete the journey to the highest stage, often functioning at a lesser level determined through interaction with their peer groups and in accord with organizational policy and legal frameworks.

At the basic pre-conventional level, the salient beneficiary for decision making is the individual and reasoning is predominantly based on maximisation of self-gain, and minimisation of personal loss. Reasoning at the conventional level acknowledges the salience of others in the organization, such as peers and supervisors, as second party beneficiaries to the psychological contract. At the highest level, post-conventional reasoning recognises the significance of universalisable values and rights, such as human rights and justice, and embraces the idea of a social contract to recognise the interconnectedness of the individual, the organization and its environment.

According to Boatright (2003), ethical principles stem from society as the basis for mutually beneficial interaction. It follows that individuals acquire their personal ethics as a result of social contact and discourse in everyday life. A number of influences are no doubt at play in this respect: parents, friends, professional peers, and other people with whom we interact. Of particular interest, given earlier discussion about the changing nature of the employment context, are the codes of professional conduct and ethics that contribute to the behaviour of individuals in their roles as employees and in serving clients. Also of interest is the possibility that such professional codes might conflict with organizational attempts, through the institutionalising of codes of ethics and conducts formulated by the organization, to prescribe normative standards of behaviour that will best serve its own interests. It is likely that on occasions an individual's personal ethics will clash with company rules and/or professional codes. In one well-documented case, the auditing firm of Arthur Andersen was accused of a conflict of interest in respect of Enron Corporation. As commented by Boatright (2003), a possible reason for the failure of Andersen to advise Enron's board of concerns they had about the conflict of interest was that Andersen "also provided consulting services that were far more lucrative than auditing" (2003, p. 139). Other examples are not difficult to find. Taking only one recent newspaper at random, we find a university accused of quelling academic freedom of speech (Fitzgerald, 2007), and a senior retail executive allegedly 'cooking the books' on the instructions of his chief executive (Speedy, 2007). In addition, Chih, Shen and Kang (2007) examine cases of accounting fraud, highlighting the need for sound corporate ethical standards.

Although these examples involve the pursuit of legal remedies through court action, the point argued here is not whether the law has been broken; rather, that there are ethics that impinge on the decision making process. Where the former is post hoc, the latter is a precursor to possible illegal actions. Clearly, the prevailing 'ethical climate' (Victor \& Cullen, 1988) in an organization can be a source of tension and psychological discomfort in cases where the organization's institutionalised code of ethics and conduct clashes with professional and personal ethical standards (Boatright, 2003; Sims \& Keon, 2000).

\section{Ethical climate}

Victor and Cullen (1988) extended Kohlberg's theory of moral development to organizations to describe types of ethical climates that exist when employees believe that certain forms of ethical reasoning or behaviour are expected standards or norms for decision-making within 
the organization. Ethical climates express those organization's policies, procedures and practices, both formal and informal, that have moral consequences, and so determine the moral criteria that both managers and employees use to understand, weigh, and make judgements regarding right behaviour within an organization (Martin \& Cullen, 2006).

In other words, an ethical climate will reflect the extent to which the ethical dimensions of organizational culture (in all its forms) have been institutionalised and embedded through the organization's socialisation processes so that "employees perceive the existence of normative patterns in the organization with a measurable degree of consensus" (Victor \& Cullen 1988, p. 103). The less developed an organization's culture is, the greater the likelihood that employee perceptions will be fragmented leading to the existence of several identifiably different ethical climate types based on organizational sub-cultures within the organization. Similarly, in the case of organizations employing people from a range of professions and occupations, welldefined normative patterns reflected in a range of professional codes of ethics and conduct may co-exist within such organizations. This means that there is likely to be potentially large variations across employees in their perceptions of what constitutes the organization's ethical climate, and that any organization is unlikely, other than in theory, to have a single operative ethical climate type (Victor \& Cullen, 1988). Addressing such variation in relation to psychological contracts goes beyond the scope of this paper. The phrase 'ethical climate' is thus limited here in meaning to that climate which reflects those formal codes and policies institutionalised by the organization for the purpose of prescribing the ethical behaviour expected of all employees.

Victor and Cullen $(1987,1988)$ identified differences in ethical climates across organizations using a two dimensional interpretive framework. Firstly, they characterised organizational decision-making in terms of three major theoretical perspectives - egoism, benevolence, and principle - derived from ethical philosophy. Egoism is based on the seeking of pleasure, often associated with Epicureanism, and applies to behaviour concerned with self-interest and selfinterest maximizing behaviour. Benevolence (or utilitarianism) is a teleological theory; it relates to consequences and the general good, and refers to behaviour concerned with the well-being of others. The principle (or deontology) perspective is also concerned with duty in respect of decisions and actions that benefit others, but through the application of universal rules, law, codes, and procedures. For the second dimension they used three levels individual, local, and cosmopolitan - at which decision-making is determined and behaviour is operationalized. At the individual level, personal beliefs and values serve as the basis for decision criteria. At the local (organizational) level, perceptions about organizational standards and norms come into play as a basis for decision criteria. At the cosmopolitan (community external to the organization) level, perceptions about a broader set of social and ethical standards and norms operate as decision criteria (Victor \& Cullen, 1987, 1988; Martin $\&$ Cullen, 2006). Applying this interpretive framework to empirical data, Victor and Cullen (1987, 1988) developed a typology of five ethical climate types and associated typical decision-making criteria (see Figure 1). 
Locus of Analysis

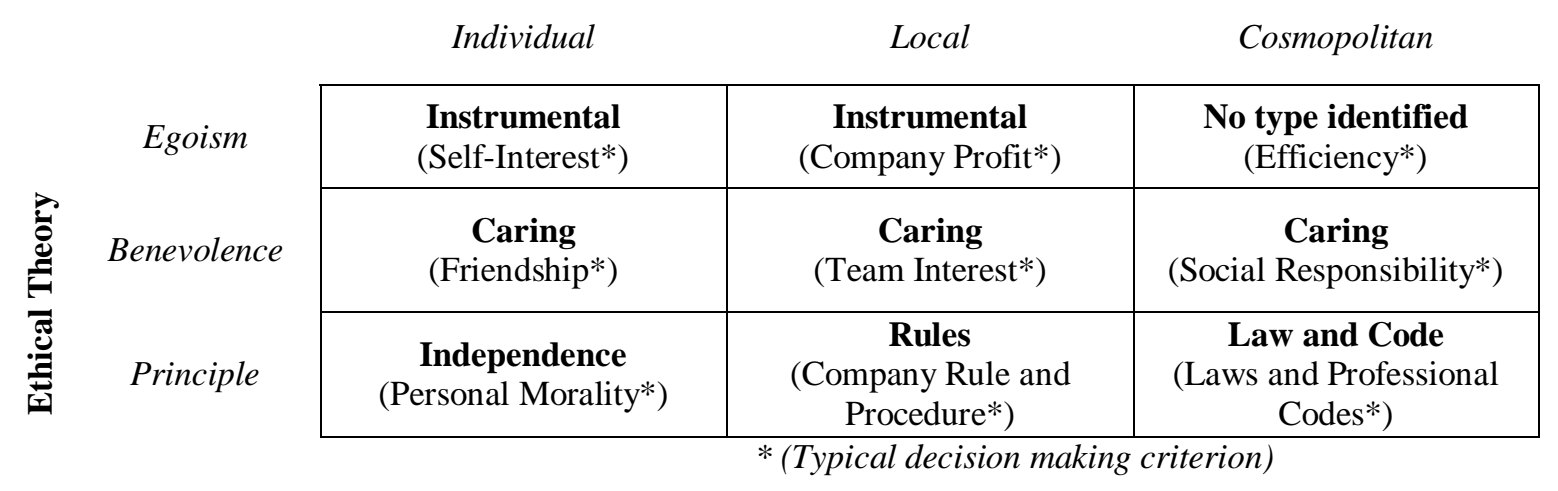

Figure 1: Ethical climates and typical decision making criteria Source: Victor and Cullen $(1987,1988)$

The 'Instrumental' ethical climate emphasises decision making that reflects an egoistic ethical perspective where self-interest is the guiding principle. The 'Caring' ethical climate emphasises decision making shaped by an overall concern for the well-being of others. The 'Independence' ethical climate emphasises decision making that uses personal moral codes to resolve ethical dilemmas. The 'Rules' ethical climate emphasises decision making consistent with organizational policies and codes of ethics and conduct. Finally, in the 'Law and code' ethical climate type, decision making that accords with legislation or professional codes is emphasised (Martin \& Cullen, 2006; Victor \& Cullen, 1987, 1988).

Viewed from the salient beneficiary perspective, the Kohlberg (1984) model and Victor and Cullen's $(1987,1988)$ typology together present a detailed picture of the range of possible beneficiaries and associated typical decision criteria that may be recognised and used in ethical decision-making at the individual and organizational levels. When joined with the expanded psychological contract interpretive framework (Thompson \& Bunderson, 2003), parallels in the frameworks can be seen (see Figure 2).

\begin{tabular}{|c|c|c|c|c|}
\hline \multicolumn{2}{|c|}{ Individual } & \multicolumn{3}{|c|}{ Organization } \\
\hline PC type & $\begin{array}{c}\text { Level of moral } \\
\text { development }\end{array}$ & $\begin{array}{c}\text { Ethical theory: } \\
\text { Egoism }\end{array}$ & $\begin{array}{c}\text { Ethical theory: } \\
\text { Benevolence }\end{array}$ & $\begin{array}{c}\text { Ethical theory: } \\
\text { Principle }\end{array}$ \\
\hline $\begin{array}{c}\text { Transactional: } \\
\text { Self }\end{array}$ & $\begin{array}{c}\text { Pre-conventional: } \\
\text { Self-interest }\end{array}$ & $\begin{array}{c}\text { Instrumental: } \\
\text { Self-interest }\end{array}$ & $\begin{array}{c}\text { Caring: } \\
\text { Friendship }\end{array}$ & $\begin{array}{c}\text { Independence: } \\
\text { Personal morality }\end{array}$ \\
\hline $\begin{array}{c}\text { Relational: } \\
\text { Self and }\end{array}$ & $\begin{array}{c}\text { Conventional: } \\
\text { Joint interest } \\
\text { (with others in the } \\
\text { Organization } \\
\text { ('We) }\end{array}$ & $\begin{array}{c}\text { Instrumental: } \\
\text { Company profit }\end{array}$ & $\begin{array}{c}\text { Caring: } \\
\text { Team interest }\end{array}$ & $\begin{array}{c}\text { Rompany policies \& } \\
\text { procedure }\end{array}$ \\
\hline $\begin{array}{c}\text { Ideology-infused: } \\
\text { Society or some } \\
\text { segment thereof } \\
\text { ('All') }\end{array}$ & $\begin{array}{c}\text { Post-conventional: } \\
\text { Community } \\
\text { (Interconnectedness } \\
\text { of self, organization } \\
\text { and environment) }\end{array}$ & (No type) & Caring: & $\begin{array}{c}\text { Law \& Code: } \\
\text { Efficiency }\end{array}$ \\
\hline
\end{tabular}

Note: Typical decision criteria shown in italics

Figure 2: Comparison of decision-making focus for psychological contracts ethical frameworks at the level of the individual and organization

Source: Adapted from Thompson and Bunderson (2003), Kohlberg (1984), and Victor and Cullen (1987, 1988) 
Specifically, the expanded interpretive psychological contract framework and Kohlberg's model define the notion of salient beneficiary for each type of contract and level of moral development respectively in terms that align with Victor and Cullen's more precise definition of the three referent levels of decision-making. In other words, the focus of the transactional psychological contract type on the 'Self' or 'Me' aligns with the Kohlberg's pre-conventional level focus on self-interest, both of which align with the individual referent level in Victor and Cullen's model of ethical climate. Similarly, the focus of the relational psychological contract type on the 'self and the organizational community' or 'We' aligns with the joint interest focus of the conventional level in Kohlberg's model aligns both of which align with Victor and Cullen's local (organization) referent level. Finally, the cosmopolitan (community external to the organization) referent level in Victor and Cullen's model aligns with the focus of the ideology-infused psychological contract type on 'society or some principle' or the 'All' and the post-conventional emphasis on community described by Kohlberg. Viewing the three theoretical frameworks in this way offers potential for clarifying the role that ethical principles, associated with each of the three main theoretical ethical perspectives, can play as an influence in the process by which an employee develops the perception that a breach of the psychological contract by the organization has occurred.

\section{Ethical frameworks and psychological contract breach}

Turnley and Feldman (1999) suggest that an employee's perception of a breach of the psychological contract will be influenced by three main factors: the sources from which the employee has derived their expectations, the nature of the specific contribution in which a discrepancy has been noted, and the characteristics of a discrepancy. According to Turnley and Feldman (1999), sources of an employee's expectations can include the employee's perceptions of the organization's culture and common practices. Drawing on the discussion of ethical frameworks above, it can be reasoned that these sources might include the individual's personal and professional ethical values and beliefs, as well as the organization's ethical climate as perceived by the employee.

With regard to the nature of the specific contribution in which a discrepancy has been noted, and consistent with the bidimensional (transactional/relational) interpretive framework, Turnley and Feldman (1999) discuss contributions that fall into one of two broad categories of 'currency' - economic or socio-emotional in nature. Again drawing on earlier discussion of an expanded interpretive framework for the psychological contract, we argue these categories can be expanded to include organizational contributions that demonstrate a commitment, to an ideological cause or principle, which is perceived by the employee as both credible and ethical.

Turning now to the third factor, the characteristics of a discrepancy, Turnley and Feldman (1999) discuss several matters, including the magnitude of any loss the employee incurs as a result of the discrepancy between what was promised and what was delivered by the organization, and the attribution that employees make with regard to the cause of the organization's failure to deliver what was promised. While Turnley and Feldman (1999) focus on losses incurred by the employee ('Me') as the salient beneficiary, it is also possible that negative impacts on the joint interest of the employee and the organization ('We') as the salient beneficiaries, or on the collective interest of the salient beneficiaries defined more broadly ('Me, We and Society') might be considered in line with the relational and ideologyinfused types of psychological contract. Thus in relation to perceptions the employee may have regarding the cause of the organization's failure to deliver what was promised, the 
ethicality of an organization's actions may be assessed, not just in terms of self-interest, in the interpretive process the employee uses to attribute cause.

The match between employees' personal ethical preferences and their perceptions of the organization's expectations in regard to ethical decision making has been the subject of research over a long period from a variety of perspectives. For example, Blake and Carroll (1989) demonstrated that unresolved conflicts between organizational expectations and employee preferences interfered with the employee's ethical decision making process. Sims and Kroeck (1994) studied the fit between personal beliefs and the perceived ethical climate of the organization, showing that a good match between the two was positively related to commitment. In a study that investigated intrapersonal role conflict as a consequence of a mismatch between an employee's own ethical beliefs and what the organization expectations were perceived to be in regard to ethical decision making, Sims and Keon (2000) illustrated the negative impact of incongruence between personal and organizational perspectives. There has been, however, little research examining incongruence using the concept of the psychological contract. In this regard, the significance of the degree of match between an employee's ethical beliefs and their perceptions of the organization's expectations or ethical climate lies in its influence on the process by which an employee concludes that the failure of an organization to meet its perceived obligations under the psychological contract represents a breach of the contract.

Figure 3 presents a model of the role of ethical frameworks as an influence in the process by which an employee elevates the perception of a discrepancy to the level of a breach of the psychological contract. 


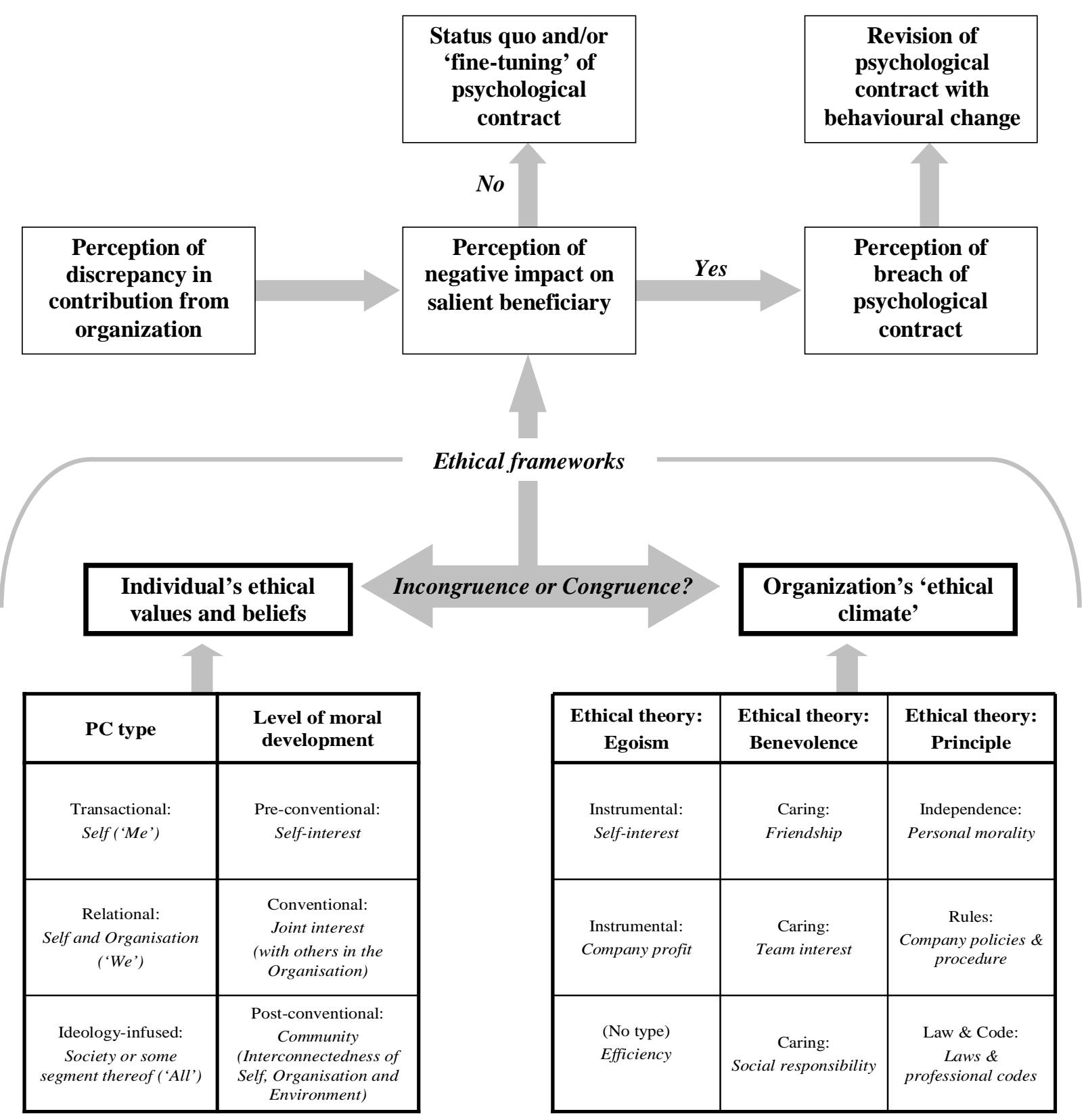

Figure 3: Ethical frameworks and psychological contract breach

The model integrates the ideas covered in the earlier sections of this paper and illustrates the role of ethical reasoning as a factor in the process of psychological contract breach by:

- representing ethics generally as a factor of influence;

- separating out, and showing an interaction between, the individual's own personal ethical framework (including professional codes of ethics) and the individual's perceptions of the organization's ethical climate (including formal organizational codes of ethics and behaviour); and,

- providing a more detailed description of the typical decision making criteria that might associate with the different psychological contract and ethical climate perspectives. 
It depicts the process commencing with the perception by the employee of a discrepancy between expected and received psychological contract contribution from organization. The employee then assesses the nature of the impact of that discrepancy on the perceived salient beneficiary - the self ('Me'), the self and organizational community ('We'), or society, some segment thereof, or an intangible principle ('All'). In so doing, the employee's ethical beliefs and perceptions of the organization's ethical climate will be factors of influence.

The criteria the employee uses to determine whether the impact is significant will be related to the type of psychological contract the employee holds, and the match between the two forms (individual and organizational) of ethical frameworks. If the impact is perceived as sufficiently negative then the discrepancy will be perceived as a breach, which in turn will lead to a reassessment of the psychological contract that may be accompanied by Exit, Voice (including internal and external whistle blowing), Loyalty, or Neglect behaviours the part of the employee. If no negative impact is perceived, then the status quo will continue, perhaps with some inconsequential 'fine-tuning' in regard to the psychological contract.

In this way, the model allows us to suggest that in regard to the psychological contract:

- where the organization's action is perceived as congruent with both the individual's ethical values and beliefs and the perceived ethical climate of the organization, the organization's action is less likely to be perceived as a breach;

- where the organization's action is perceived as incongruent with both the individual's ethical values and beliefs and the perceived ethical climate of the organization, the organization's action is action more likely to be perceived as a breach;

- notwithstanding the impact of the organization's socialisation processes, where there is incongruence between the individual's ethical beliefs and the perceived ethical climate of the organization, cognitive dissonance will ensue. This is most likely to result in the individual's personal ethical values having dominance over the organization's expectations as the key influencing factor, and perceptions of a breach if the negative impact is adjudged by the individual as significant.

\section{Implications}

In terms of implications for psychological contract theory, this discussion highlights the need to recognise the ethical dimension more fully if a better understanding of the complexity of the relationship between employees and their organization is to be obtained. To date in psychological contract research there has been quite a lot of attention paid to the justice dimensions (distributive, procedural, etc) using the bidimensional (transactional/relational) interpretive framework (see for example Kickul, 2001). By extending the justice approach to include possible consideration of alternatives - utilitarianism, moral rights, and universalism, the proposed model has potential as a focus for future research into the process of breach.

From the perspective of the management practitioner, two matters deserving of consideration emerge from this analysis of the psychological contract and ethics. One relates to the source of deeply internalised personal ethics within individuals, the other to a clash of professional ethics and organizational requirements. As stated by Robbins (2005, p. 71), "Individuals enter an organization with preconceived notions of what 'ought' and what 'ought not' to be. Of course, these notions are not value-free. On the contrary, they contain interpretations of right and wrong." Ideas of right and wrong based on, say, devoutly held religious, cultural or professional value-based beliefs have the potential to disrupt organizational operations profoundly. In such cases, organizational attempts to socialise employees and establish normative patterns of ethical behaviour may prove problematic. This presents difficulties for 
management in resolving tensions in the best interests of the organization, without offending the individuals concerned to the point where a perceived breach of the psychological contract occurs.

These management difficulties may be exacerbated in a globalised world where organizations traverse national borders and the opportunity exists for perceptions to differ on ethical standards. Several authors draw attention this issue where ethical standards vary between countries (Desai \& Rittenburg, 1997; Napal, 2005; Jackson, 2000). In one case it was found that ethical standards differed between nationalities of managers according to the nationality of their home country rather than the host country and, further, that corporate policy had little influence on managers' ethical attitudes and decisions, with very little variation across cultures (Jackson, 2000). The link between values and ethics is further emphasised by Payne (1988) who examined various measures of values and attitudes and their linkage to ethics. A point to be made here is that employees recruited from the host-country may quite well have different views from parent-country nationals on what is 'ethical', thus producing a tension that has the potential to disrupt the organization's operations.

On the second matter, regarding professional codes of ethics, we have already pointed out recent cases of clashes between demands of employers and employees. In such dilemmas, employees must make a choice between the perhaps unethical requirements of their organization and that of their profession. Breach and violation of the psychological contract can occur in such circumstances, leading to the outcomes listed in Figure 2. The implications here are twofold.

Firstly, the importance of achieving consistency in the type of employment relationship the organization is seeking with its employees and the type of ethical climate it wishes to develop is highlighted. For example, imagine, say, a professional nurse employee with an ideologyinfused psychological contract that recognises the interconnectedness of the provision of health care with the broader community in which the employer - let us say a profit-oriented private hospital organization - operates. Consistent with professional commitment, the nurse employee's personal ethical perspective aligns with the 'Principle' or 'Benevolence' theoretical perspectives focusing on professional ethics and social responsibilities. This compares with the employer's approach which, say, pursues efficiency supported by an ethical climate such as the 'Instrumental' or 'Rules' types that emphasise company profit and policies as the main decision criteria. The potential for psychological breach, and ensuing negative behavioural responses, arising from such incongruence in ethical frameworks is clear.

Secondly, unless and until organizations adopt transparently ethical business practices that reflect congruence between organizational and professional values, they and their employees may face the danger of transgressing the law and/or being reported to regulatory and professional bodies for malpractice. To be sure, there is evidence of training in business ethics (Gandz \& Hayes, 1988; Maclagan, 2002; Petrick \& Scherer, 2005; Warren \& Tweedale, 2002; Rossouw \& van Vuuren, 2003; Payne, 1988); however, training based on the organization's view of 'ethics' may be insufficient. The critical factor, therefore, is not so much ethics as narrowly determined by the organization in terms of its own business interests, but that organizations need to be aware of ethical tensions placed on individuals, whether stemming from their professional obligations, or their personal ethical standards. Unfortunately, as long as some organizations are principally driven by the desire for profit 
above all else, there may be little progress in achieving ethical business practices that do not violate psychological contracts.

\section{References}

Anderson, N. and R. Schalk: 1998, 'The psychological contract in retrospect and prospect', Journal of Organizational Behaviour 19(S1), p637-647.

Ashmos, D.P. and D. Duchon: 2000, 'Spirituality at work: a conceptualisation and measure', Journal of Management Inquiry 9(2), 131-145.

Blake, R. B. and D. A. Carroll: 1989, 'Ethical reasoning in business'. Training \& Development Journal 43(6), 99-104.

Bloor, G. and P. Dawson: 1994, 'Understanding professional culture in organizational context', Organization Studies 15(2), 275-294.

Boatright, J. R.: 2003, Ethics and the conduct of business, $4^{\text {th }}$ edition (Prentice Hall, Upper Saddle River NJ).

Bunderson, J. S.: 2001, 'How work ideologies shape the psychological contracts of professional employees: doctors' responses to perceived breach', Journal of Organizational Behaviour 22(7), 717-741.

Burr, R. and P. Thomson: 2002, 'Expanding the network: what about including 'the all' in the psychological contract', Paper presented at the Academy of Management Conference, Denver, USA.

Chih, H-L., C-H. Shen, and F-C. Kang: 2007, 'Corporate social responsibility, investor protection, and earnings management: some international evidence', Journal of Business Ethics (online) DOI 10.1007/s10551-007-9383-7.

Collier, J. C. and R. Esteban: 2007, 'Corporate social responsibility and employee commitment', Business Ethics: A European Review 16(1), 19-33.

Coyle-Shapiro, J., L. M. Shore, M. S. Taylor and L. E. Tetrick (Eds.): 2004, The employment relationship: examining psychological and contextual perspectives, (Oxford, New York).

Desai, A. B. and T. Rittenburg: 1997, 'Global ethics: an integrative framework for MNEs', Journal of Business Ethics 16(8), 791-800.

Fitzgerald, R.: 2007, 'Uni disables a basic freedom: outspoken academics are entitled to be heard', The Australian, 14 August, p. 12.

Ford Motor Company: 2007, http://www.ford.com/doc/corporate_conduct_standards.pdf, $25 / 10 / 2007$

Gandz, J. and N. Hayes: 1988, 'Teaching business ethics', Journal of Business Ethics 7(9), 657-669. 
Hewlett-Packard: 2007, http://www.hp.com/hpinfo/globalcitizenship/csr/sbcbrochure.pdf, $25 / 10 / 2007$

Jackson, T.: 2000, 'Management ethics and corporate policy: a cross-cultural comparison', Journal of Management Studies 37(3), 349-368.

Kickul, J.: 2001, 'When organizations break their promises: employee reactions to unfair processes and treatment', Journal of Business Ethics 29(4), pp. 289-307.

Kohlberg, L.: 1984, The psychology of moral development: Nature and validity of moral stages, (Harper and Row, San Francisco).

Maclagan, P.: 2002, 'Reflections on the integration of ethics teaching into a British undergraduate management degree programme', Teaching Business Ethics 6(3), 297318.

Marks, A.: 2001, 'Developing a multiple foci conceptualisation of the psychological contract', Employee Relations 23(5), 454-467.

Martin, K. D. and J. B. Cullen: 2006, 'Continuities and extensions of ethical climate theory: a meta-analytic review', Journal of Business Ethics 69(2), 175-194.

McLean Parks, J., D. L. Kidder and D. G. Gallagher: 1998, 'Fitting square pegs into round holes: mapping the domain of contingent work arrangements onto the psychological contract', Journal of Organizational Behaviour 19, 697-730.

Millward, L. J. and P. M. Brewerton: 2000, 'Psychological contracts: employee relations for the $21^{\text {st }}$ century' in C. L. Cooper and I. Robertson (eds), International Review of Industrial and Organizational Psychology 15, (John Wiley \& Sons, Chichester), 1-63.

Morrison, E. W. and S. L. Robinson: 1997, 'When employees feel betrayed: a model of how psychological contract develops', Academy of Management Review 22(1), 226-256.

Napal, G.: 2005, 'An assessment of power abuse under ethics philosophies', Electronic Journal of Business Ethics and Organization Studies 10(1), 29-34.

Payne, S. L.: 1988, 'Values and ethics-related measures for management education', Journal of Business Ethics 7(4), 273-277.

Petrick, J. A. and R. F. Scherer: 2005, 'Management educators' expectations for professional ethics development', Journal of Business Ethics 61(4), 301-314.

Robbins, S. P.: 2005, Organizational behavior, 11th edition, (Pearson Prentice Hall, Upper Saddle River NJ).

Robinson, S. L. and D. M. Rousseau: 1994, 'Violating the psychological contract: not the exception but the norm', Journal of Organizational Behaviour 15, 245-259. 
Rossouw, G. J. and L. J. van Vuuren: 2003, 'Modes of managing morality: a descriptive model of strategies for managing ethics', Journal of Business Ethics 46(4), 389-402.

Rousseau, D. M. and S. A. Tijoriwala: 1998, Assessing psychological contracts: issues, alternatives and measures', Journal of Organizational Behaviour 19(S1), 679-695.

Rousseau, D. M.: 1995, Psychological contracts in organizations, (Sage Publications, Thousand Oaks).

Rousseau, D. M.: 2001, 'Schema, promise and mutuality: the building blocks of the psychological contract', Journal of Occupational and Organizational Psychology 74, 511-541.

Sims, R. L. and T. L. Keon: 2000, 'The influence of organizational expectations on ethical decision making conflict', Journal of Business Ethics 23(2), 219-228.

Sims, R. L. and K. G. Kroeck: 1994, 'The influence of ethical fit on employee satisfaction, commitment and turnover', Journal of Business Ethics 13(12), 939-947.

Sims, R.: 1991, 'The institutionalization of organizational ethics', Journal of Business Ethics 10(7), 493-506.

Speedy, B.: 2007, 'Coles boss accused over fake numbers', The Australian, 14 August, p. 3.

Takala, T.: 2006, 'Editorial: an ethical enterprise - what is it?', Electronic Journal of Business Ethics and Organization Studies 11(1), p. 4.

Taylor, S. M. and A. G. Tekleab: 2004, 'Taking stock of psychological contract research: assessing progress, addressing troublesome issues, and setting research priorities', in J. A-M. Coyle-Shapiro, L. M. Shore, M. S. Taylor \& L. E. Tetrick (eds): 2004, The employment relationship: examining psychological and contextual perspectives, (Oxford, New York), pp. 253-283.

Thompson, J. A. and J. S. Bunderson: 2003, 'Violations of principle: ideological currency in the psychological contract', Academy of Management Review 28(4), 571-587.

Turnley, W. H. and D. C. Feldman: 1999, 'A discrepancy model of psychological contract violations', Human Resource Management Review 9(3), 367-386.

Victor, B. and J. B. Cullen: 1987, 'A theory and measure of ethical climate in organizations', in W. Kurtines and J. Gewirtz (eds): 1987, Morality, Moral behaviour, and moral development, (Wiley, New York), pp. 201-281.

Victor, B. and J. B. Cullen: 1988, 'The organizational bases of ethical work climates', Administrative Science Quarterly 33(1), 101-125.

Warren, R. and G. Tweedale: 2002, 'Business ethics and business history: neglected dimensions in management education', British Journal of Management 13(3), 209-219. 
Weinberg, J. R. and K. E. Yandell: 1971, Ethics: problems in philosophical inquiry Volume III, (Holt, Reinhart and Winston, New York). 